\title{
INDICADORES AMBIENTAIS PARA O INSTITUTO FEDERAL DE EDUCAÇÃO, CIÊNCIA E TECNOLOGIA DO RIO GRANDE DO NORTE
}

\author{
M. V. G. OLIVEIRA ${ }^{1}$, G. L. P. CAMELO ${ }^{2}$ \\ Instituto Federal de Educação, Ciência e Tecnologia do Rio Grande do Norte \\ valiene.oliveira@ifrn.edu.br ${ }^{1}$,gerda.camelo@ifrn.edu.br ${ }^{2}$
}

Artigo submetido em 25/11/2019 e aceito em 24/12/2019

DOI: $10.15628 /$ holos.2019.9205

\section{RESUMO}

O objetivo do trabalho é propor um conjunto de indicadores ambientais para mensurar a gestão hídrica e energética e a gestão de resíduos sólidos para o ambiente organizacional com foco na área de ensino, no caso, o Instituto Federal de Educação, Ciência e Tecnologia do Rio Grande do Norte. No contexto institucional no qual o trabalho se insere, considera-se que esse esforço propiciará a instituição envolvida a implementação de uma ferramenta adequada para a mensuração da dimensão ambiental dos eixos estabelecidos, dispondo assim de competências necessárias para abordar, melhorar, instigar o tema da preservação dos recursos naturais. Destacam-se como resultados: um conjunto consistente de indicadores de resultados para mensuração das variáveis propostas, visando a efetiva implementação e melhoria contínua no processo de acompanhamento do desempenho ambiental da Instituição.

PALAVRAS-CHAVE: Indicadores ambientais, Gestão hídrica, Gestão energética, Resíduos sólidos.

\section{ENVIRONMENTAL INDICATORS FOR THE FEDERAL INSTITUTE OF EDUCATION, SCIENCE AND TECHNOLOGY OF RIO GRANDE DO NORTE}

\begin{abstract}
The objective of this paper is to propose a set of environmental indicators to measure water, energy and solid waste management for the organizational environment with focus on the teaching area, in this case, the Federal Institute of Education, Science and Technology of Rio Grande do Norte. In the institutional context in which the work is inserted, it is considered that this effort will provide the institution involved with the implementation of an appropriate tool to measure the
\end{abstract}

environmental dimension of the axes involved, thus having the necessary skills to address, improve, instigate the theme of preservation of natural resources. The following stand out as results: a consistent set of result indicators to measure the proposed variables, aiming at the effective implementation and continuous improvement in the process of monitoring the environmental performance of the Institution.

KEYWORDS: Environmental indicators, Water management, Energy management, Solid waste. 


\section{INTRODUÇÃO}

A modernização requer uma grande quantidade de bens de consumo, como: estrada, casas, edifícios, automóveis, eletroeletrônicos, alimentos e até mesmo na prestação de serviço. A produção destes está baseada em um fluxo constante de processamento ou, podemos chamar de etapas no seu ciclo produtivo. Cada etapa do ciclo, até o seu descarte final, gera impactos ambientais que aliados à exploração acelerada dos recursos naturais, permite a escassez dos mesmos, desencadeando um desequilíbrio ambiental e ocasionando vários acidentes ambientais, mudanças climáticas, dentre outros problemas que estão ocorrendo em várias partes do mundo. Diante do exposto, o reconhecimento de uma gestão ambiental em cada atividade desenvolvida ajudará a minimizar os seus efeitos catastróficos que a sua escassez pode causar.

Segundo Tocchetto (2004), os indicadores de desempenho ambiental representam medidas que auxiliam a qualidade e expressam um desempenho eficaz na gestão ambiental das organizações. Se elas não têm um planejamento ambiental satisfatório, seus objetivos tendem a ficar prejudicado e as perdas na sua maioria são irreparáveis. Dentre os ambientes organizacionais, destaca-se as atividades de ensino que segundo consta na Agenda 21, "o ensino é também fundamental para conferir consciência ambiental e ética, valores e atitudes, técnicas e comportamentos em consonância com o desenvolvimento sustentável e que favoreçam a participação pública efetiva nas tomadas de decisão" (AGENDA 21 GLOBAL, 1992).

Nos meados de 60, representantes de várias universidades nas regiões do mundo tornaram público o interesse e sua preocupação com as causas ambientais através da declaração de Talloires, constando a importância em dirigir ações a estes problemas para reverter os impactos ambientais causados pelo desenvolvimento acelerado (THE TALLOIRES DECLARATION, 1990). Na área educacional é muito importante que a mesma possa ser modelo de preservação ambiental e reconhecida pela sociedade como um importante exemplo de desenvolvimento sustentável.

Levando em consideração as informações acima, no estado do Rio Grande do Norte podese citar o Instituto Federal de Educação, Ciência e Tecnologia do Rio Grande do Norte (IFRN), uma organização acadêmica de ensino, pesquisa e extensão, com categoria administrativa pública e, atuando no cenário acadêmico há mais de 100 anos, comprometida com a formação de pessoas, com o exercício da cidadania, com a produção e a socialização do conhecimento. Sabe-se que o mesmo vem implementando iniciativas ambientais pontuais e constatou-se, por pesquisa documental, que na sua gestão ambiental não existe indicadores para mensurar as atividades que vêm sendo desenvolvidas, ficando, dessa forma, difícil de entender melhor a sua evolução, possíveis tendências e uma posterior amplitude de suas ações ambientais (IFRN, 2015).

Os indicadores ambientais têm a finalidade de representar numericamente, em quantidade, qualidade ou consumo, os impactos relacionados ao setor e suas respectivas ações. Esses indicadores estão relacionados à utilização de recursos naturais e visam reduzir os impactos ambientais través dos dados apresentados, geridos e acompanhados pelos seus gestores (GASPARINI, 2003).

A importância em realizar estudos que visam analisar o uso de água, energia e resíduos em instituições de ensino é relevante devido ao número de usuários circulantes e o grande período de tempo que os mesmos, a utilizam. Diante dos fatos, é primordial que as instituições tenham uma 
gestão ambiental incorporada às suas metas estratégicas, com medidas que possam amenizar os impactos ambientais causados por suas atividades, devendo para tanto, mensurar o seu desempenho através de indicadores que possibilitará um resultado visível de suas ações, tornandose um importante veículo de conscientização, provocador para novas pesquisas e implantação de um espirito de conscientização e preservação ambiental.

\section{REVISÃO BIBLIOGRÁFICA}

\subsection{MEIO AMBIENTE E RECURSOS NATURAIS}

O desenvolvimento econômico foi propagado com o objetivo de atingir o tão sonhado e esperado alto padrão de vida. Em contrapartida, pouco foi exposto para a população às consequências desse avanço, que veio consumindo os recursos naturais como se eles fossem inesgotáveis, ocorrendo assim, a exploração irracional dos mesmos e prejudicando toda a vida do planeta. Assim, sem percebermos, criou-se um problema de crise ambiental pela aceitação ingênua de que o lucro pode ser obtido a todo custo (PHILIPPI JR.; BRUNA, 2014).

O recurso natural surge através de um processo natural e sua apropriação ocorre segundo valores sociais, através da interação sociedade-natureza para suprir a necessidade humana. Segundo Dulley (2004), a natureza seria um conjunto de condições que envolvem e sustentam os seres vivos na biosfera, como um todo ou em parte desta, abrangendo elementos do clima, solo, água, sendo o meio ambiente, a soma total das condições externas com as quais os organismos interagem.

\subsection{GESTÃO AMBIENTAL}

A gestão ambiental é aqui explicitada como uma abordagem integrada, que procura abranger, simultaneamente, as questões que interferem no meio ambiente - natural ou construído - bem como as interações envolvendo diferentes sistemas. $O$ fato de envolver diversas áreas que compõem o complexo ambiental é que fornece as bases para dar início ao estabelecimento de gestão ambiental, fundamentados na integração físico-territorial, social, político, econômico e cultural (PHILIPPI JR.; BRUNA, 2014).

Para fortalecer o conceito de gestão ambiental, Naime (2004) descreve como um conjunto de procedimentos que permite a uma organização administrar adequadamente sua relação entre as atividades desenvolvidas e o meio ambiente na qual está inserida, atentando para zelar pela legislação e boas práticas e as expectativas das partes. Para auxiliar na gestão ambiental, eficiente e eficaz, surgem os indicadores, que servem para expressar e comunicar, de maneira simples e objetiva, as características essenciais na ocorrência do fato, evolução do uso do recurso, significado dos seus efeitos e a importância socioambiental desse fenômeno aos gestores e à sociedade. 


\subsection{INDICADOR}

O termo indicador é originário do latim indicare, que significa apontar, descobrir, anunciar, estimar. Os indicadores cumprem o objetivo na melhoria da comunicação entre entidades organizacionais e a sociedade, promovendo a discussão de temas complexos, nos quais existe uma necessidade de consenso comum, acerca da estratégia a ser trabalhada. Para tanto, um indicador deve tornar perceptível um fenômeno não detectável em termos imediatos, tendo uma ação mais objetiva do que os fornecidos apenas pela observação direta, expresso por formas estatísticas ou gráficos (ADRIAANSE, 1993).

Para Van Bellen (2005), os indicadores devem ser entendidos como variáveis com a sua representação operacional de atributos, como qualidade, característica e propriedade de um sistema, com objetivo de agregar e quantificar informações, ressaltando sua significância, visando melhoria no processo e no entendimento dos fenômenos tratados. Os indicadores devem ser analisados através de sistemas, que permitam verificar a interdependência da variável para gerar resultados confiáveis e que retratem a realidade investigada do fenômeno estudado.

Segundo Tauk (1991), um indicador ambiental é uma variável especifica para cada fator ambiental, permitindo um acompanhamento do comportamento e suas aferições, tornando-se um elemento essencial para a análise qualitativa e quantitativa das variações ambientais. Dessa forma, ao quantificar ou qualificar as oscilações de um indicador ambiental, se estabelece uma medida da intensidade de um impacto ambiental para um estudo analítico-comparativo.

\subsection{VARIÁVEIS AMBIENTAIS}

Os conflitos por causa da água são constante e agravam-se com o aumento significativo quanto ao seu consumo somando-se ao agentes poluidores e mudanças climáticas. Eles estão por todo o mundo, independente das diferenças entre contextos sociais, geográficos ou ambientais, cabendo destacar uma preocupação com o uso racional da água como forma de sua preservação, refletindo o que a doutrina denomina de cidadania ambiental ou ecológica (DI CARLI, 2015).

Na Conferência Rio+10 (2002), Cúpula Mundial de Desenvolvimento Sustentável, foi ratificada pelos participantes a proposta da meta de redução de $50 \%$ no número de pessoas que à época não tinham acesso a água de boa qualidade e que não dispunham de redes de esgotos. Nesta ocasião, foi proposto que os países desenvolvidos apoiassem os países em desenvolvimento na monitorização e avaliação dos recursos hídricos, incluindo o desenvolvimento de indicadores.

A outra variável desta pesquisa é a energia considerada essencial para o desenvolvimento humano, social e econômico e o controle dos gases que provocam o efeito estufa e de outros gases e substâncias deverá basear-se cada vez mais na eficiência, produção, transmissão, distribuição e consumo da energia sobretudo de fontes de energia novas e renováveis, esse conjunto de ações e iniciativas deve basear-se numa boa gestão energética. Os investimentos no desenvolvimento de tecnologias limpas impulsionam a redução de emissões desses gases corroborando para a harmonia com um modelo de crescimento aderente também às necessidades do setor produtivo e do planeta (CEBDS, 2012). 
Além da energia, devemos considerar que não é uma tarefa simples gerenciar o recurso natural que dispomos. A preservação do solo associa-se, em boa parte, a uma gestão eficiente dos resíduos/rejeitos gerados. A preocupação mundial em relação aos resíduos tem aumentado em face do crescimento de sua geração, desde a conferência Rio-92, que os países têm priorizado o conceito de gestão integrada de resíduos sólidos. Outro aspecto muito relevante é o apoio à inclusão dos catadores de materiais que prioriza a participação das cooperativas em atendimento ao Decreto no 5.940/2006, ressalta-se aqui da importância de uma gestão ambiental de qualidade para enfrentar os desafios da preservação dos recursos naturais, na busca de um processo de interação entre as atividades desenvolvidas pelo homem e o meio ambiente (BRASIL, 2012).

\subsection{SISTEMAS E SEUS INDICADORES AMBIENTAIS}

As metodologias ajudam em um melhor entendimento das questões complexas que envolvem o meio ambiente. Elas conseguem integrar as partes, auxiliando na visão onde o ambiente está inserido. Bollmann (2001), sugere que os elementos na natureza não podem ser analisados somente com a soma de suas partes, e que novos modelos de conhecimento auxiliam para um melhor entendimento das questões mais complexas.

Do ponto de vista teórico e conceitual, está pesquisa trabalhou com diversos modelos já consagrados por diversas universidades e organizações, dentre os quais, destacamos: Instituto ETHOS; International Organization for Standardization - ISO 14031:2004; Universidade de Sustentabilidade da UI Ranking (GreenMetric), Report Card Faculdade de Sustentabilidade, Painel Nacional de Indicadores Ambientais (PNIA) e Federação e Centro das indústrias do Estado de São Paulo (Fiesp/Ciesp). Para avaliar a dimensão ambiental é imprescindível que se faça a escolha adequada dos indicadores a serem utilizados, apresentamos um resumo, no quadro 1 , dos indicadores ambientais que fizeram parte da matriz de seleção desta pesquisa.

Quadro 1 - Indicadores ambientais para elaboração da matriz de seleção

\begin{tabular}{l|l|c}
\hline \multicolumn{1}{c|}{ Modelo } & \multicolumn{1}{c|}{ Resumo } & $\begin{array}{c}\text { Indicadores } \\
\text { ambientais }\end{array}$ \\
\hline ETHOS & $\begin{array}{l}\text { Têm como foco a área empresarial, numa atuação que visa } \\
\text { apoiar as empresas na incorporação da sustentabilidade }\end{array}$ & 42 \\
\hline ISO 14031 & $\begin{array}{l}\text { A norma é utilizada quando uma organização busca gerenciar } \\
\text { com responsabilidade e quer alcançar seus resultados } \\
\text { almejados no seu sistema de gestão ambiental. }\end{array}$ & 13 \\
\hline GREENMETRIC & $\begin{array}{l}\text { Utiliza uma pesquisa “online”, com a intenção de avaliar as } \\
\text { políticas e condições atuais nas universidades de todo o mundo } \\
\text { em prol da sustentabilidade. }\end{array}$ & 16 \\
\hline REPORT CARD & $\begin{array}{l}\text { Sustentabilidade em profundidade para mais de 300 faculdades } \\
\text { em todos os 50 estados dos EUA e oito províncias canadenses. }\end{array}$ & 24 \\
\hline PNIA & $\begin{array}{l}\text { Objetivo é organizar e consolidar a produção e divulgação de } \\
\text { informações e reunir um conjunto de indicadores de referência } \\
\text { na área ambiental }\end{array}$ & 07 \\
\hline
\end{tabular}




\begin{tabular}{l|l|c}
\hline FIESP & $\begin{array}{l}\text { Indicadores de desempenho ambiental na indústria no intuído } \\
\text { de melhorar a produtividade, competividade e mostrar da } \\
\text { importância do acompanhamento ambiental da mesma. }\end{array}$ & 10 \\
\hline
\end{tabular}

Analisando os 112 indicadores apresentados, observa-se, em linhas gerais, um conjunto de indicadores abrangentes e pertinentes relacionados ao desempenho ambiental para o gerenciamento da água, energia e resíduo sólido viáveis para qualquer organização, gerando resultados confiáveis e que retratem a realidade investigada.

\section{METODOLOGIA}

\subsection{MEIO AMBIENTE E RECURSOS NATURAIS}

A preservação e o uso racional dos recursos naturais dependem do comportamento de uma sociedade que seja compatível com seu meio ambiente e que tenha condições de produzir os bens e os serviços básicos para a existência e a sobrevivência humana, sem recorrer ao desperdício e à política obsoleta, características inerentes à sociedade de consumo contemporânea (RATTNER, 1977).

Quanto aos fins, a pesquisa é considerada descritiva e aplicada, de acordo com Vergara (2002) e quanto aos meios de investigação, foram utilizados: pesquisa bibliográfica, pesquisa documental e estudo de caso. Na primeira fase da pesquisa, foi realizada a fundamentação teórica, com o objetivo de verificar o estado da arte dos conceitos e pesquisas relacionadas à avaliação de desempenho ambiental nas organizações, mais especificamente, nas instituições de ensino. Com temas voltados para a pretensão da pesquisa, ou seja, identificar estudos e documentos com foco no desempenho ambiental, bem como, os modelos e ferramentas de avaliação adotadas no mundo e no Brasil.

Após escolhidos os indicadores ambientais "candidatos", utilizou-se o instrumento de coleta de dados uma matriz de avaliação garantindo a confiabilidade nos resultados, evitando distorções de análise e interpretação, permitindo, assim, uma margem de segurança considerável quanto às deduções, procurando enumerar e/ou medir os eventos estudados na análise dos dados (GODOY, 1995). A seleção dos indicadores aconteceu de forma participativa e foi aplicada com os servidores da Instituição e especialistas na área de cada variável pretendida.

Apresenta-se como resultado da pesquisa um conjunto de indicadores para compor a avaliação da dimensão ambiental $\mathrm{A}$ aplicação de indicadores pode apoiar na tomada de decisão quanto à definição de metas e instrumentos para planejar, gerenciar e monitorar, bem como, minimizar os impactos decorrentes de seu gerenciamento inadequado.

\subsection{ANÁLISE DOS RESULTADOS}


Nesta etapa são apresentados os indicadores selecionados necessários a realidade da organização do estudo de caso para a variável água, energia e resíduo sólido.

\subsubsection{Indicadores de água}

Tendo como base apresentar o objetivo geral da pesquisa, nesta etapa são apresentadas as análises dos indicadores da variável água, dessa forma, a análise do quadro 2 indica que os respondentes desta pesquisa selecionaram indicadores necessários na realidade da organização em que trabalham. Dentre os 24 (vinte e quatro) indicadores candidatos, propostos pela pesquisa foram selecionados 5 (cinco) para a variável água que representa $21 \%$ do total da amostra da pesquisa.

Quadro 2: Médias, desvios padrão e coeficientes de variação da variável água

\begin{tabular}{l|c|r|r|r}
\hline \multicolumn{1}{c|}{ Indicadores de água } & Unidade medida & Média & \multicolumn{1}{c|}{ Desvio } & \multicolumn{1}{c}{ CV\% } \\
\hline Programa de conservação de água & $\mathrm{N}^{\circ} / \mathrm{ano}$ & 52,00 & 1,63 & 3,14 \\
\hline Consumo total de água & $\mathrm{m}^{3} / \mathrm{ano}$ & 56,33 & 5,31 & 9,43 \\
\hline Água tratada consumida & $\mathrm{m}^{3} / \mathrm{ano}$ & 56,67 & 5,73 & 10,12 \\
\hline $\begin{array}{l}\text { Realizar ações para instalação de novas tecnologias e } \\
\text { instalação do uso de aparelhos eficientes de água }\end{array}$ & Quant . ano ${ }^{-1}$ & 66,67 & 7,54 & 11,31 \\
\hline Volume total de efluentes líquidos & $\mathrm{m}^{3} / \mathrm{ano}$ & 53,67 & 6,65 & 12,39 \\
\hline
\end{tabular}

Fonte: dados pesquisa (2016)

Pode-se sugerir ainda que houve uma baixa variação nos valores entre os indicadores escolhidos, isto é, o intervalo compreendido foi de 3,14\% a 12,39\% da análise dos dados. Percebese a luz da teoria que ocorreu um baixo valor no coeficiente de variação tornando os dados mais homogêneos, ou seja, houve uma baixa dispersão em torno da média dos mesmos.

O indicador "Programa de conservação de água" também teve sua definição no PNCDA, constando no DTA o tema planejamento e gestão e articulação institucional das ações de conservação e uso racional da água, este indicador é bastante significativo pela busca de acompanhamentos para caracterizar o consumo de água na edificação ou outras iniciativas planejadas que busquem alternativas para o consumo de água ou seu reaproveitamento e sim algumas ações pontuais que vão sendo implantadas.

O indicador "consumo total de água" visa garantir exatidão no monitoramento do consumo, esse conhecimento, em um edifício, auxilia a reconhecer perdas por vazamentos ou falhas no sistema. Este indicador também é contemplado pelo Programa Nacional de Combate ao Desperdício de Água (PNCDA), ação do Governo Federal, 1997.

Segundo Jardim (2013), estudos indicam que cerca de 1.500 substâncias são lançadas anualmente no mundo, muitas delas são novas e não existem estudos de suas causas nos seres humanos. Assim, diariamente, os mananciais recebem toneladas de diversos tipos de resíduos, diante do exposto é de suma importância o surgimento do indicador "água tratada consumida" possibilitando o acompanhamento e a identificação da qualidade da água consumida possibilitando uma intervenção no abastecimento predial quando for necessário. 
O indicador "realizar ações para instalação de novas tecnologias e instalação do uso de aparelhos eficientes de água" é bastante relevante, pois, busca alternativas para minimizar o consumo da água que reflete na economia financeira. Para Oliveira (1999), essas ações tecnológicas contribuem para a redução de consumo de água em edifícios, gerando grande impacto e, ainda melhoria no atendimento às necessidades dos usuários.

Baseando-se nas referências teóricas e empíricas estudadas são diversas as iniciativas que buscam alternativas para o consumo de água, seja na sua redução do consumo, bem como na sua substituição de água para os usos não potáveis, o indicador "volume total de efluentes líquidos" surge como uma necessidade de acompanhamento para que o instituto possa verificar as diversas possibilidades de reuso dos seus efluentes, o manual de Conservação e Reuso de Águas em Edificações contempla várias dessas possibilidades (ANA, FIESP; SINDUSCON, 2005).

Em relação a variável água foi possível identificar indicadores que vão ao encontro de um monitoramento para uma gestão adequada do recurso hídrico. Depreende-se de acordo com as teorias e legislações especificas que correlatam como princípio básico de assegurar a disponibilidade de água para suprir as necessidades humanas atuais e futuras (BRASIL,1997; TUCCI,2003; UNCED, 1992).

\subsubsection{Indicadores de energia}

Dando continuidade à base do objetivo geral, nesta etapa são apresentadas as análises dos indicadores da variável energia, dessa forma, a análise do quadro 3 indica que os respondentes desta pesquisa identificaram uma amostra considerada relevante. Dos 38 indicadores candidatos foram selecionados 16 para a variável energia o que representa $42 \%$ do total de indicadores propostos pela pesquisa.

Quadro 3: Médias, desvios padrão e coeficientes de variação da variável energia

\begin{tabular}{|c|c|c|c|c|}
\hline Indicadores de energia & Unidade medida & Média & Desvio & CV\% \\
\hline $\begin{array}{l}\text { Realizar investimentos no desenvolvimento de } \\
\text { novas tecnologias com foco em redução do } \\
\text { consumo de energia }\end{array}$ & R\$/ano & 51,67 & 4,78 & 9,26 \\
\hline $\begin{array}{l}\text { Ter um acompanhamento de proporção do uso } \\
\text { total de eletricidade no sentido de campus } \\
\text { população }\end{array}$ & Kw . população-1 & 63,00 & 7,35 & 11,66 \\
\hline $\begin{array}{l}\text { Participação da energia produzida a partir de } \\
\text { fontes renováveis na matriz energética }\end{array}$ & $\begin{array}{l}\text { Kwh renovável } \\
\text { (Kwh renovável + } \\
\text { Kwh COSERN }) * 100\end{array}$ & 63,00 & 7,35 & 11,66 \\
\hline Quantidade de energia usada por ano & Kwh/ano & 66,00 & 8,49 & 12,86 \\
\hline Usar energia com aparelhos eficientes & Kwh/mês & 66,00 & 8,49 & 12,86 \\
\hline $\begin{array}{l}\text { Implementação de um programa de construção } \\
\text { inteligente }\end{array}$ & Quant . ano ${ }^{-1}$ & 66,00 & 8,49 & 12,86 \\
\hline $\begin{array}{l}\text { Instalação de energia solar, eólica, geotérmica, } \\
\text { ou de outras fontes alternativas de energia ou } \\
\text { fora do campus }\end{array}$ & $\mathrm{R} \$ / \mathrm{Kw}$ & 66,00 & 8,49 & 12,86 \\
\hline
\end{tabular}




\begin{tabular}{|c|c|c|c|c|}
\hline Indicadores de energia & Unidade medida & Média & Desvio & CV\% \\
\hline $\begin{array}{l}\text { Possuir planos de ação formalizados para } \\
\text { reduzir o consumo de energia direta }{ }^{1}\end{array}$ & Quant . ano ${ }^{-1}$ & 60,67 & 8,06 & 13,28 \\
\hline $\begin{array}{l}\text { Promover investimentos buscando evoluir no } \\
\text { uso de novas fontes de energia renováveis e } \\
\text { limpas }\end{array}$ & $\mathrm{R} \$ / \mathrm{W}$ & 60,67 & 8,06 & 13,28 \\
\hline Ter uma política de uso de energia renovável & Quant . ano-1 & 60,67 & 8,06 & 13,28 \\
\hline Possuir programa de conservação de energia & Quant . ano-1 & 60,67 & 8,06 & 13,28 \\
\hline $\begin{array}{l}\text { Possuir elemento de aplicação de construção } \\
\text { verde }\end{array}$ & Quant. ano ${ }^{-1}$ & 60,67 & 8,06 & 13,28 \\
\hline $\begin{array}{l}\text { Possuir planos de ação formalizados para } \\
\text { reduzir o consumo de energia indireta }{ }^{2}\end{array}$ & Quant . ano-1 & 63,33 & 9,57 & 15,11 \\
\hline
\end{tabular}

Fonte: dados pesquisa (2016)

Pode-se sugerir ainda que houve uma baixa variação nos valores entre os indicadores escolhidos, isto é, o intervalo compreendido foi de $9,26 \%$ a $15,11 \%$ da análise dos dados. Percebese a luz da teoria que ocorreu um baixo valor no coeficiente de variação tornando os dados mais homogêneos, ou seja, houve uma baixa dispersão em torno da média dos mesmos. A energia é essencial para o desenvolvimento humano, social e econômico e o controle, dos gases que provocam o efeito estufa e de outros gases e substâncias, deverá basear-se cada vez mais na eficiência, produção, transmissão, distribuição e consumo da energia sobretudo de fontes de energia novas e renováveis (BRASIL, 2013).

Os indicadores propostos pela pesquisa tais como: Realizar investimentos no desenvolvimento de novas tecnologias com foco em redução do consumo de energia; Participação da energia produzida a partir de fontes renováveis na matriz energética; Usar energia com aparelhos eficientes; Instalação de energia solar, eólica, geotérmica, ou de outras fontes alternativas de energia ou fora do campus; Promover investimentos buscando evoluir no uso de novas fontes de energia renováveis e limpas; Ter uma política de uso de energia renovável vão ao encontro no rumo da mudança para o cenário mundial de mudanças climáticas, bem como, as proposta da agenda do CEBDS e do Governo Federal impulsionando a redução de emissões de gases do efeito estufa.

Já os indicadores "ter um acompanhamento de proporção do uso total de eletricidade no sentido de campus população" e "quantidade de energia usada por ano" fornecem a compreensão na forma de cobrança da energia elétrica e como são calculados os valores nas faturas, eles são fundamentais para tomada de decisão em relação a projetos de eficiências energéticas, através desta análise é possível estudar a relação entre os hábitos e consumo de uma edificação predial e o resultado obtido é importante para verificar se a relação contratual está adequada ao consumo,

\footnotetext{
${ }^{1}$ Energia direta acontece pela utilização de equipamentos e maquinários, na operação de termelétricas, na frota de veículos e em outras operações (Eletrobrás, 2013)

${ }^{2} \mathrm{~A}$ energia indireta refere-se ao consumo por meio de fontes intermediárias, ou seja, a energia consumida em forma de eletricidade (Eletrobrás, 2013)
} 
e em alguns casos resultam em menor despesa com a energia elétrica quando existe um novo enquadramento tarifário (CEPEL 2010).

O edifício sustentável é aquele capaz de proporcionar benefícios na forma de conforto, funcionalidade, satisfação e qualidade de vida sem comprometer a infraestrutura gerando o mínimo possível de impacto no meio ambiente em busca de autonomia, e os indicadores de "implementação de um programa de construção inteligente" e "possuir elemento de aplicação de construção verde" vêm para auxiliar no planejamento do ambiente construído respeitando o meio ambiente e promovendo a qualidade de vida para a edificação, através deles será possível disseminar as tecnologias alternativas de aproveitamento da luz natural, ventilação natural, aquecimento solar para água e outras formas que possam promover eficiência energética.

Todos os conceitos de sustentabilidade acrescidos aos edifícios terão a viabilidade maximizada se aplicados efetivamente e um fator essencial para o sucesso da implantação das soluções é ter um programa com uma metodologia que possibilite a avaliação e reformulação das soluções ao longo de todo o processo permitindo a interação entre todos os profissionais envolvidos. Os indicadores "possuir programa de conservação de energia; possuir planos de ação formalizados para reduzir o consumo de energia direta e possuir planos de ação formalizados para reduzir o consumo de energia indireta" contemplam esse conjunto de ações e instrumentos de conservação de energia buscando formas para caracterizar o consumo de energia na edificação ou outras iniciativas planejadas que busquem alternativas para a eficiência energética ou seu reaproveitamento do projeto em questão.

\subsubsection{Indicadores de resíduo sólido}

Dando continuidade à base do objetivo geral, nesta etapa são apresentadas as análises dos indicadores da variável resíduo sólido, dessa forma, a análise do quadro 4 indica que os respondentes desta pesquisa identificaram uma amostra considerada relevante. Dos 49 indicadores candidatos, propostos pela pesquisa, foram selecionados 16 para a variável resíduo o que representa $32,65 \%$ do total de indicadores propostos.

Quadro 4: Médias, desvios padrão e coeficientes de variação da variável resíduo sólido

\begin{tabular}{|c|c|c|c|c|}
\hline Indicadores de resíduo sólido & $\begin{array}{l}\text { Unidade } \\
\text { medida }\end{array}$ & Média & Desvio & CV\% \\
\hline $\begin{array}{l}\text { Quantidade de materiais processados, reciclados ou } \\
\text { reutilizados }\end{array}$ & $\mathrm{kg} \cdot \mathrm{ano}^{-1}$ & 67,44 & 3,36 & 4,98 \\
\hline Monitorar a geração de resíduos & Quant . ano ${ }^{-1}$ & 67,11 & 3,50 & 5,21 \\
\hline Realizar coleta seletiva & Quant . ano ${ }^{-1}$ & 67,00 & 3,56 & 5,31 \\
\hline $\begin{array}{l}\text { Quantidade de resíduos perigosos, recicláveis ou } \\
\text { reutilizáveis por ano }\end{array}$ & $\mathrm{kg} \cdot \mathrm{ano}^{-1}$ & 66,67 & 4,99 & 7,48 \\
\hline $\begin{array}{l}\text { Quantidade de resíduos convertidos em material } \\
\text { reutilizável por ano }\end{array}$ & $\mathrm{kg} \cdot \mathrm{ano}^{-1}$ & 66,67 & 4,99 & 7,48 \\
\hline Tratamento de resíduos inorgânico (lixo) & t. ano ${ }^{-1}$ & 66,67 & 4,99 & 7,48 \\
\hline Atender à legislação de destinação adequada de resíduos & Quant . ano ${ }^{-1}$ & 64,44 & 6,00 & 9,30 \\
\hline Tratamento de resíduos orgânicos (lixo) & t. ano ${ }^{-1}$ & 65,33 & 6,24 & 9,55 \\
\hline Política para reduzir o uso de papel e plástico no campus & Quant . ano ${ }^{-1}$ & 63,89 & 6,67 & 10,44 \\
\hline
\end{tabular}




\begin{tabular}{|c|c|c|c|c|}
\hline Indicadores de resíduo sólido & $\begin{array}{l}\text { Unidade } \\
\text { medida }\end{array}$ & Média & Desvio & CV\% \\
\hline Quantidade de resíduos para disposição & $\begin{array}{l}\text { Kg resíduos } \\
\text { Kg rejeitos } \\
\text { gerados }^{-1}\end{array}$ & 64,44 & 7,07 & 10,97 \\
\hline Acompanhar a taxa de reciclagem de resíduos tóxicos & $\begin{array}{l}\text { taxa de } \\
\text { reciclagem } \\
\text { de resíduos } \\
\text { tóxicos }\end{array}$ & 64,44 & 7,07 & 10,97 \\
\hline $\begin{array}{l}\text { Quantidade de resíduos perigosos eliminados devido à } \\
\text { substituição de material }\end{array}$ & t. ano ${ }^{-1}$ & 63,56 & 7,08 & 11,15 \\
\hline Monitorar o consumo de materiais & Quant . ano-1 & 62,67 & 8,22 & 13,12 \\
\hline Quantidade de resíduos armazenados no local & t. ano ${ }^{-1}$ & 62,44 & 8,51 & 13,63 \\
\hline $\begin{array}{l}\text { Administração de um programa de reciclagem para todos } \\
\text { os campus e refeitório recicláveis tradicionais, tais como } \\
\text { garrafas, latas e papelão }\end{array}$ & Quant . ano-1 & 59,11 & 9,31 & 15,75 \\
\hline $\begin{array}{l}\text { Proporcionar a reciclagem para itens como baterias, } \\
\text { telefones celulares, computadores e cartuchos de } \\
\text { impressora, dos resíduos produzidos pelos alunos e pela } \\
\text { escola }\end{array}$ & Quant . ano ${ }^{-1}$ & 59,11 & 9,31 & 15,75 \\
\hline
\end{tabular}

Fonte: dados pesquisa (2016)

Pode-se sugerir ainda que houve uma baixa variação nos valores entre os indicadores escolhidos, isto é, o intervalo compreendido foi de 4,98\% a 15,75\% da análise dos dados. Percebese a luz da teoria que ocorreu um baixo valor no coeficiente de variação tornando os dados mais homogêneos, ou seja, houve uma baixa dispersão em torno da média dos mesmos.

Um dos objetivos fundamentais estabelecidos pela Política Nacional dos Resíduos Sólidos (PNRS) é a obrigatoriedade na gestão dos resíduos desde a sua geração, redução, reutilização, reciclagem, tratamento chegando a sua disposição final ambientalmente adequada dos rejeitos. Como papel também relevante é o apoio à inclusão dos catadores de materiais que prioriza a participação das cooperativas determinando a separação de resíduos recicláveis descartados de órgãos e entidades da administração pública em benefício de associações e cooperativas de catadores de material reciclável (BRASIL, 2012).

O conjunto de indicadores gerados pela pesquisa para a variável resíduos sólidos garante a participação e o controle social do IFRN, buscando o cumprimento das metas estabelecidas no PNRS e demais metas previstas em legislação correlatas. Somando-se ao movimento nacional de transformação dos cenários e padrões de produção, consumo, tratamento e destinação dos resíduos, a fim de encontrarem soluções sustentáveis e permanentes para otimizar a gestão dos resíduos sólidos urbanos.

A pesquisa destaca-se por apresentar um conjunto consistente de indicadores para a mensuração da dimensão ambiental, visando um adequado controle de gestão dos resíduos sólidos urbanos para uma melhoria contínua no processo de mudança e preservação dos recursos naturais, contemplando as reais necessidades de suas atividades para que o resultado possa embasar e consolidar a sua gestão ambiental. 


\section{CONSIDERAÇÕES FINAIS}

O presente trabalho de pesquisa contribuiu para o avanço do conhecimento empírico sobre a importância da mensuração da dimensão ambiental para preservação dos recursos naturais em um ambiente educacional, ao propor um conjunto de indicadores que permitem medir os esforços para uma gestão eficiente nas variáveis água, energia e resíduo sólido. Os resultados obtidos ao longo da pesquisa possibilitaram o alcance geral da dissertação. A seleção do tipo de estudo de caso, a delimitação da análise e seus referenciais balizadores mostram-se adequados. A base conceitual sobre a importância de gerir a dimensão ambiental num ambiental educacional foram de grande valia para a definição das questões sobre a atuação das instituições de ensino no viés com a preocupação na conservação dos recursos naturais.

O conhecimento sobre os modelos para análise da sustentabilidade norteou a proposição de um conjunto de indicadores robusto, pertinente, inspirado nas estruturas conceituais do: Instituto ETHOS; International Organization for Standardization - ISO 14.031:2004, Universidade de Sustentabilidade da UI Ranking (GreenMetric), Report Card Faculdade de Sustentabilidade, Painel Nacional de Indicadores Ambientais (PNIA) e Federação e Centro das indústrias do Estado de São Paulo (Fiesp/Ciesp). Esses contribuíram significativamente para que os objetivos específicos da dissertação fossem alcançados.

Com relação ao debate do papel que as instituições de ensino têm na dissipação e implementação de práticas de preservação do meio ambiente, foi possível ressaltar a importância de uma boa gestão ambiental. $\mathrm{O}$ ambiente educacional encontra-se em posição privilegiada para melhorar o comportamento humano, dispondo de competências necessárias para abordar, melhorar, instigar o tema da preservação dos recursos naturais. Essa constatação foi expressa e referendados no corpo da dissertação.

Para fins da adoção sistemática do modelo conceitual para mensuração da sustentabilidade no IFRN, recomenda-se:

- $\quad$ a avaliação sistemática do resultado da implementação dos indicadores;

- criação de mecanismos de comunicação institucional dos resultados alcançados, com base no acompanhamento dos indicadores de resultados;

- $\quad$ definição de um plano de ação com base nas recomendações anteriores.

Na expectativa da replicação do modelo conceitual como prática inovadora de gestão em outros ambientes educacionais, recomenda-se sua ampla divulgação junto aos principais grupos de interesse, dentre outros. Finalmente, para trabalhos futuros de desdobramento e aprofundamento dos resultados, propõem-se:

- identificar oportunidades para que esses indicadores possam gerir índices para com essa inovação gerir um grau de sustentabilidade, podendo evidenciar mais objetivamente a importância de cada componente do modelo sistêmico, permitindo atribuir pesos aos constructos;

- $\quad$ ampliar o escopo da sistemática de avaliação, incluindo indicadores de outras dimensões e ampliar os da dimensão ambiental, a exemplo variável atmosférica e processamento de dados; 
- monitorar a evolução dos modelos e práticas de avaliação de sustentabilidade;

São imprescindíveis instrumentos de auxílio ao processo decisório, facilitando a comunicação e a compreensão da realidade ao ambiente inserido. $O$ trabalho baseou-se na investigação e discussão do potencial informativo dos indicadores como instrumentos de gestão da dimensão ambiental. Esse suporte foi construído ao longo da pesquisa, e concretizado através do levantamento das informações disponíveis. As atividades devem buscar harmonia com a natureza, portanto, a busca por métodos existentes e criar novos procedimentos organizacionais é de grande relevância, com reflexos diretos na qualidade ambiental.

\section{REFERÊNCIAS}

ASSOCIAÇÃO BRASILEIRA DE NORMAS TÉCNICAS. NBR ISO 14.031. Gestão ambiental - avaliação de desempenho ambiental - diretrizes. Primeira ed. Rio de Janeiro, 2004.

ASSOCIAÇÃO CATARINENSE DAS FUNDAÇÕES EDUCACIONAIS. Como atuam as comunitárias. Disponível em: < http://www.universidadecomunitaria.com.br>. Acesso em: 12 set. 2015.

AGENCIA NACIONAL DE ÁGUAS. Cadernos de recursos hídricos. Disponibilidade e demandas. Brasília, 2005. Disponível em:

<http://www2.ana.gov.br/Paginas/servicos/planejamento/estudos/cadernoderecursos.aspx>. Acesso em: 26 maio 2017.

ASSOCIATION OF UNIVERSITY LEADERS FOR A SUSTAINABLE FUTURE. The talloires declaration, 1990. Disponível em: <http://ulsf.org/programs_talloires.html>. Acesso em: 16 jan. 2016.

BRASIL. Ministério do Meio Ambiente. Instituto de Energia e Meio Ambiente. Brasília, 2013. Disponível em:< http://www.mma.gov.br/port/conama/processos/C1CB3034/Apres_IEMA_Zamboni.pdf>. Acesso em: 23 out. 2015.

. Ministério do Meio Ambiente. Painel nacional de indicadores ambientais. Brasília, DF, 29 jan. 2013. Disponível em:<http://www.mma.gov.br/publicacoes/pnia>. Acesso em: 24 mai. 2016.

Ministério do Meio Ambiente. Plano de gestão de resíduos sólidos: manual de orientação. Brasília, DF, 2012. Disponível em:< http://www.mma.gov.br/estruturas/182/_arquivos/manual_de_residuos_solidos3003_182.pdf>. Acesso em: 24 mai. 2016.

. Ministério do Meio Ambiente. Proteção da atmosfera. Agenda 21 global. Capítulo 9. Brasília, DF, 2013. Disponível em: <http://www.mma.gov.br/responsabilidadesocioambiental/agenda-21/agenda-21-global> Acesso em 09 set 2015. 
Ministério do Meio Ambiente. Um recurso cada vez mais ameaçado. Brasília. Disponível em:<http://www.mma.gov.br/images/noticias_arquivos/banner_pnia_2012.pdf>. Acesso em: 26 mai. 2017.

Ministério do Planejamento, Orçamento e Gestão. Indicadores de Programas: guia metodológico/Ministério do Planejamento, Orçamento e Gestão, Secretaria de Planejamento e Investimentos Estratégicos. Brasília, DF, 6 mar. 2010. Disponível em:<http://www.orcamentofederal.gov.br/programa-esplanada-sustentavel/sispes>. Acesso em: 24 mai. 2016.

. DECRETO № 5.940, de 25 de outubro de 2006. Disponível em:

http://www.planalto.gov.br/ccivil_03/_Ato2004-2006/2006/Decreto/D5940.htm.

CENTRO DAS INDÚSTRIAS DO ESTADO DE SÃO PAULO. Indicadores de desempenho ambiental das indústrias. São Paulo, 2011. Disponível em:< http://www.ciesp.com.br/pesquisas/indicadores-dedesempenho-ambiental-na-industria/>. Acesso em: 16 fev. 2016.

CONSELHO EMPRESARIAL BRASILEIRO PARA O DESENVOLVIMENTO SUSTENTÁVEL. Energia renovável: entraves, desafios e oportunidades. Rio de Janeiro: 2016. Disponível em:<http://cebds.org/wpcontent/uploads/2016/05/CEBDS_SUM_FINANCIAMENTO_A_ENERGIA_RENOV\%C3\%81VELentraves_desafios_oportunidades_SITE.pdf>. Acesso em: 26 maio 2017.

DI CARLI, A, A. Água é vida eu cuido, eu poupo: para um futuro sem crise. Primeira ed. Rio de Janeiro: Editora FGV, 2015.

GASPARINI, L. V. L. Analise das interelações de indicadores econômicos, ambientais e sociais para o desenvolvimento sustentável. 2003. 221 f. Dissertação (Mestrado em Engenharia de Produção), Universidade Federal de Santa Catarina, Florianópolis, 2003.

Como elaborar programas de pesquisa. 4. ed. São Paulo: Atlas, 2009.

GODOY, A. S. Introdução à pesquisa qualitativa e suas possibilidades. Revista de Administração de Empresas. São Paulo, v. 35, n. 2, abril,1995.

INSTITUTO ETHOS. Indicadores ethos de responsabilidade social empresarial 2007. São Paulo, 2007. Disponível em:<http://www3.ethos.org.br>. Acesso em: 14 nov. 2015.

INSTITUTO FEDERAL DE EDUCAÇÃO, CIÊNCIA E TECNOLOGIA DO RIO GRANDE DO NORTE. Política socioambiental. 2015. Disponível em:< http://portal.ifrn.edu.br/servidores/campusverde/politica-socioambiental-do-ifrn>. Acesso em: 14 nov. 2015.

JARDIM, W. F. Qualidade da água consumida pelos brasileiros. Oficina do eixo meio ambiente, clima e vulnerabilidades. São Paulo, Unicamp: 2013. Disponível em: <http://www.mobilizadores.org.br/wp-content/uploads/2014/05/cartilha-agua-final.pdf>. Acesso em: 26 maio 2017. 
NAIME, R. Diagnóstico ambiental e sistemas de gestão ambiental. 6. ed. Novo Hamburgo, RS: FEEVALE, 2004.

OLIVEIRA, L. H. Metodologia para a implantação de programa de uso racional da água em edifícios. Boletim Técnico da Escola Politécnica da USP, Departamento de Engenharia de Construção Civil, BT/PCC/227. São Paulo: EPUSP, 1999.

RATTNER, H. O esgotamento dos recursos naturais: catástrofe interdependência? Revista de Administração de Empresas. Rev. Adm. Empres. v.17 n.2, São Paulo Mar./Abr. 1977. Disponível em: <http://www.scielo.br/scielo.php?script=sci_arttext\&pid=S0034-75901977000200002>. Acesso em: 29 fev. 2016.

REPORT CARD. PENN STATE GREEN DESTINY COUNCIL. Pena State Indicators Report 2000. Steps towar a sustainable university. Disponível em< http://www.willamette.edu/ nboyce/assessment/PennState.pdf>. Acesso em: 9 maio 2016. PHILIPPI JR., A.; BRUNA, G. C. Curso de gestão ambiental. 2. ed. atual e ampl. São Paulo: Manole, 2014.

TAUK, S. M. Análise ambiental: uma visão multidisciplinar. São Paulo: Editora Universidade Estadual Paulista: FAPESP; SRT; FUNDUNESP, 1991.

THE COLLEGE SUSTAINABILITY REPORT CARD. Explore the report card. Disponivel em: < 2011https://translate.google.com.br/translate?hl=pt-

BR\&sl=en\&u=http://www.greenreportcard.org/report-card-2011.html\&prev=search>. Acesso em: 16 jan. 2016.

TOCCHETTO, M. R. L.; TOCCHETTO A. L.; PEREIRA, L. C. Indicadores de desempenho ambiental para empresas com atividade galvânica. In: Congresso acadêmico sobre o meio ambiente e desenvolvimento, 2004, Rio de Janeiro. Anais..., Rio de Janeiro, 2004.

TUCCI, C. E. M.; SILVEIRA, A. L. L. et al. Hidrologia: ciência e aplicação. 3. ed. 1. reimp, Porto Alegre: Ed. da UFRGS/ABRH, 2003.

UNCED. UNITED NATIONS CONFERENCE ON ENVIRONMENT AND DEVELOPMENT. Agenda 21. Rio de Janeiro, 1992. Disponível em: <

http://www.meioambiente.pr.gov.br/arquivos/File/agenda21/Agenda_21_Global_Integra.pdf >. Acesso em: 29 fev. 2016.

VAN BELLEN, H. M. Indicadores de sustentabilidade: uma análise comparativa. 2. ed. Rio de Janeiro: Editora FGV, 2005.

VERGARA, S.C. Metodologia do trabalho científico. 2. ed. São Paulo: Cortez, 2002. 